1975 do not simply derive from 1975 censuses. Rather they are extrapolations from the 1973 UN Demographic Yearbook, itself based on data up to 10 years old; the Environmental Fund's projections forward from 1973 derive from actual growth in numbers of people (from Table 4 of the 1973 UN Demographic Yearbook), rather than the more theoretically derived birth and death rates given in the latest UN estimates (April 1, 1975). The most significant uncertainty is in the figures for China.

In mid-1975, the total world population stood at around 4,147 million, growing at an annual rate of $2.2 \%$. The dominant contribution was from Asia, whose 45 countries contributed 2,407 million people, with an overall growth rate of $2.5 \%$; the growth rates of individual countries were scattered about this weighted average rate with a standard deviation of about $\pm 0.7 \%$. Other major geographical regions are Africa with 50 countries, 420 million people, growth rate $2.8 \%$; and Latin America with 30 countries, 328 million people, and growth rate of $2.9 \%$. The more developed regions are the 27 European countries, comprising 474 million people with an overall average growth rate of $0.8 \%$; North America with 242 million and growth rate $1.0 \%$; the USSR with 254, and $0.9 \%$; and Oceania (comprised mainly of Australia) with 21 million people growing at $2.1 \%$ per annum. In each of these major regions, the growth rates of individual countries are scattered around the weighted mean value with standard deviations in the range $0.6-0.7$; thus European rates span a range from -0.4 to 2.6, Latin American from 1.0 to 3.5 , African from 1.2 to 3.8 .

Of the larger countries (and henceforth I shall use "larger" to mean in excess of 10 million inhabitants), the top 1975 growth rate was Pakistan, at $3.6 \%$. Despite its tribulations, South Vietnam was a close runner-up at 3.5 , followed by Iraq and Kenya with $3.4 \%$. In the open division of this event, regardless of the country's population, the clear winner was Kuwait with $4.8 \%$ (produced in part by immigration), from Libya on 3.8 and Rhodesia on 3.7. At the other end of the scale was East Germany with a negative population growth rate of $-0.4 \%$, followed by Portugal with -0.3 , Hungary with 0.1 , and Sweden and the United Kingdom on 0.2 .

These different growth rates, past and present, make for great sociological differences in the countries. One important index of this is the fraction of the population which is under 15 years of age. In the world as a whole, $37 \%$ of people are under 15 . By region, this breaks down into $44 \%$ in Africa, 43 in Latin America, and 40 in Asia,

\title{
Natural selection and evolution
}

KREBS and May's account of social insects and the evolution of altruism (Nature, 260, 9; 1976) is excellent, but the first paragraph raises a controversial issue. They attack statements of the type 'adaptations evolve because they are of benefit to the species (or population) as a whole'. They go on to point out, rightly, that natural selection acts on individuals, not on populations, but they then say: "Natural selection is a matter of differential survival and reproduction of individuals (or to be precise of genes), not of species". Evolution occurs over many generations, however, and genes do not exist in isolation but are part of gene complexes to which they must be adapted. Since most organisms reproduce sexually there will be many different gene complexes in the population over several generations. So for a gene to maintain its differential survival (that is, to increase its frequency or be selected) it must be adapted to many gene complexes, in other words to the entire gene pool of the population. This is what is meant by saying that an adaptation evolves because it benefits the population as a whole.

This point is important because a number of authors, particularly American ones, interpret 'adaptations benefitting populations' as implying group selection as defined by Wynne-Edwards (Animal Dispersion in relation to Social Behaviour, Oliver and Boyd, 1962). I have

in systematic contrast with $26 \%$ in Europe, 27 in North America, 29 in the USSR, and 33 in Oceania. The top numbers are held by Iraq and Mexico, with a staggering $48 \%$ of the population below the age of 15 ; a dozen other countries (mainly in Latin America) follow with $47 \%$. At the opposite end, Hungary has $20 \%$, and East Germany and Sweden $21 \%$. This ratio, which may crudely be thought of as a ratio of "tax consumers" to "tax producers", has a multitude of obvious implications for the social organisation of a country, some of which have been explored by Watt (Principles of Environmental Science, McGraw-Hill, New York, 1974) and others.

Maudlin (Studies in Family Planning, 6, 30-36; 1975) has catalogued the developing countries according to the official government position regarding population growth or support of family planning. It is encouraging that 34 of these 118 countries, accounting for myself recently been criticised on these grounds (Dingle, Science, I88, 1105 ; 1975), yet I never once mentioned group selection. There is an important distinction between natural selection, which relates to individuals or gene complexes, and evolution, which relates to changes in populations or in gene pools. When people write about adaptations evolving because they benefit the population or the species, this should not be thought to imply that they do not understand Darwinian natural selection, but rather that they are stressing the integration of the genes responsible for the adaptation into the gene pool.

\section{Malcolm Edmunds}

JOHN KREBS REPLIES : Edmunds is correct in pointing out that good genes are ones which not only code for good characters, but also get on well with their fellow genes. However, selection does not act on large gene complexes, because they do not survive long enough as single units. Genes last a long time, so they are the units which survive in the process of natural selection. Where genes are very closely coadapted, they evolve very strong linkage so as to become one supergene.

Well adapted gene pools and gene complexes are obviously a consequence of natural selection for good genes, but this does not mean that gene pools and complexes are the basic unit of natural selection.

2,083 million people (or $74 \%$ of the total among developing countries), have an announced policy to reduce population growth rates. In the case of India, the policy reaches back to 1952 ; 23 others date from the 1960 s, and the remaining 10 from the $1970 \mathrm{~s}$. The average 1975 rate of population growth in this first category of developing countries was $2.6 \%$. A second list of 32 countries (total population 454 million, representing $16 \%$ of people in developing countries) have official support for some form of family planning activities for reasons other than reducing population growth. The average growth rate in this category of "less alarmed" countries is $2.8 \%$. A third category, including 52 countries (although only 270 million people, or $10 \%$ of those in developing countries) does not even have support for family planning.

It is notable that so large a fraction of the developing countries has adopted policies aimed at reducing 